\title{
No Centenário da Morte de Mendeleev: a Dicotomia Cósmica na sua Tabela Periódica
}

A. M. Amorim da Costa*

Na Tabela Periódica de Mendeleev está patente o carácter dual do Amor e do Ódio dos Antigos ou da "conjugação dos opostos" dos alquimistas que alternadamente une e separa os elementos no seu devir entre o Uno e o Múltiplo: os elementos alcalinos e alcalino-terrosos à esquerda; os halogéneos e calcogéneos à direita. De um lado os elementos electronegativos, ávidos de electrões; do outro, os electropositivos. À direita, os não-metais, moles, sem brilho nem dureza; à esquerda, os metais, duros e brilhantes e notável poder de condução. A separá-los, os metalóides, híbridos em que se misturam os caracteres dicotómicos de uns e outros.

\section{INTRODUÇÃO}

Celebraram-se no ano de 2007, cem anos sobre a morte de Dmitri Ivanovich Mendeleev (Fev.1834 - Jan.1907) a que Posin, em 1948, se referiu como a partida de um venerável e muito sábio homem, com uma barba quase tão longa quanto a do próprio Deus, que montado numa grande gota de água, foi ao encontro do grande Senhor do Universo para a pedido e em nome do seu povo, Ihe dar conta da miséria em que viviam os seus concidadãos [1]. Todos quantos algum dia tiveram um contacto mínimo com o mundo da Química ter-se-ão deparado quase inevitavelmente com essa figura venerável de longas barbas à Pai Eterno; e também com as figuras rabiscadas da Tabela Periódica que apresentou em 1869 à comunidade científica [2]. A história e o significado desta Tabela são bem conhecidos e abundantemente documentados, incluindo as preciosas considerações que o próprio autor sobre ela teceu, já quando a apresentou à comunidade científica, já em vários escritos que sobre o assunto escreveu nos anos que se seguiram a essa apresentação, com particular relevo para os escritos de 1879,1881 e 1889 [3].

O modo mais adequado que Eric $\mathrm{R}$. Scerri encontrou para assinalar, no ano de 2007, os cem anos sobre a morte de Mendeleev foi precisamente a publicação de um volumoso livro sob o título The Periodic Table: Its Story and Its Significance [4] em que analisa as ideias fundamentais, quer científi-

\footnotetext{
Dept. Química, Universidade de Coimbra, 3004-535 Coimbra, Portuga acosta@ci.uc.pt
}

cas, quer filosóficas, que estiveram patentes em todo o processo evolutivo da classificação dos elementos químicos, concretizada em diversos tipos de quadros e tabelas do número das quais a de Mendeleev viria a assumir a predominância e o grande protótipo daquela que é mais usada nos nossos dias [5]. Não vou aqui debruçar-me sobre a interessantíssima análise apresentada neste livro de Scerri. Nem sequer pretendo sublinhar a minha concordância ou discordância com alguns dos pressupostos em que ela se apoia. Como químico que reconhece no Corpo dos Tratados Alquímicos muitas das raízes do desenvolvimento e da fundamentação da Química actual, gostaria tão somente de dar o meu apoio ao esforço com que o autor, na qualidade de filósofo da ciência, tenta mostrar que a Química, particularmente a Química que informa o sistema da classificação periódica dos elementos apoiada nas teorias do atomismo moderno, "é profundamente diferente da Física e é, em particular, resistente às generalidades dedutivas que a Física oferece". Nesse sentido, permito-me trazer para aqui algumas especulações de autores cujo envolvimento na elaboração do sistema da classificação periódica dos elementos se apoiou muito em razões de ordem filosófica, quase votados ao esquecimento pelo positivismo das ciências experimentais.

O ATOMISMO E A CLASSIFICAÇÃo PERIÓDICA DOS ELEMENTOS QUÍMICOS

Se em 2007 se celebraram cem anos sobre a morte de D. Mendeleev, em 2008 celebram-se duzentos sobre o estabelecimento do atomismo de John Dalton (1766-1844) que mudaria a face da ciência química lavoisieriana, com a publicação do primeiro volume do seu tratado A New System of Chemical Philosophy [6]. Segundo este " todos os corpos são formados de pequenas partículas ou átomos de matéria que se repelem mutuamente com uma força que aumenta à medida que a distância entre elas diminui. Um átomo dum elemento pode unir-se com um, dois, três ou quatro átomos de um outro elemento, mas nunca com fracções de átomos". Esta "engenhosa ideia de Mr. Dalton", na expressão de Humphry Davy (1778-1829) [7], mereceu a melhor das atenções dos químicos do século XIX que a ela aderiram com grande entusiasmo e convicção. Desenvolvida em todas as suas partes e consequências, ela foi usada muito especialmente na explicação das diferentes combinações dos átomos elementares na formação dos compostos químicos e conhecimento da fórmula atómica de qualquer composto em geral. Não pararam mais as tentativas de quantificação da interacção entre essas pequenas partículas ou átomos de matéria.

Muito naturalmente, o primeiro passo foi determinar o peso relativo dos átomos dos diferentes corpos, tomando o peso atómico de um deles para termo de comparação. A tarefa não foi fácil, nem o consenso foi imediato. E os métodos a que se recorreu para o fazer foram diversos, com alguma disputa sobre qual deles seria o mais apropriado. Nessa determinação se envolveu a grande maioria dos químicos do século XIX, particularmente durante a primeira metade deste. Determinado o número relativo dos áto- 
mos elementares de um composto, procedeu-se, nomeadamente, à determinação da relação entre as quantidades ponderáveis dos seus elementos, como o fizeram, em particular, o próprio J. Dalton, J.J. Berzelius (1779-1848) e seus colaboradores mais próximos [8]; à determinação da relação dos volumes desses mesmos elementos no estado gasoso com base nos estudos de J. Gay-Lussac (1778-1850) [9]; à determinação da relação entre o peso do átomo e a capacidade calorífica do corpo em análise, com P.L.Dulong (1785-1838) e A.T. Petit (1791-1820) à cabeça [10]; e à determinação da relação das quantidades ponderáveis de compostos isomórficos, num procedimento liderado por A.Mitscherlich (1794-1863) [11]. Estabelecidas tabelas com os pesos atómicos dos elementos químicos, de imediato começaram a surgir tabelas de classificação destes tendo por base os pesos atómicos conhecidos e as classificações dos elementos químicos em termos de propriedades equivalentes. Rapidamente, em vez de se considerarem estas como base da classificação passou-se a procurar a sua explicação nas relações encontradas entre os próprios pesos atómicos.

Para esta diferente orientação na caracterização e classificação dos elementos muito contribuíram, entre outros, William Prout (1785-1850), o primeiro a sugerir, numa publicação não assinada, aparecida em 1815 , nos Anais de Filosofia de Thomson [12], que todos os pesos atómicos seriam múltiplos inteiros exactos do peso atómico do hidrogénio, pressupondo uma regularidade na constituição dos diferentes elementos. Desta regularidade resultariam caracteres similares entre os elementos que poderiam ser tomados como base experimental duma possível classificação e caracterização.

Neste sentido avançou J. W. Döbereiner (1780-1849) [13] depois de observar que a tríade de elementos cálcio, estrôncio e bário apresentava muitos caracteres semelhantes e com a particularidade do estrôncio, o elemento médio da tríade, apresentar um peso atómico muito próximo da média dos pesos atómicos dos outros dois elementos que dela faziam parte.
Em 1850, Max von Pettenkoffer (1818-1901) [14] notava que o peso atómico de vários elementos semeIhantes diferiam entre si por um múltiplo de 8:

$\mathrm{Li}=7 ; \mathrm{Na}=7+16$ (=23); $\mathrm{K}=23+16$ ou, então, $\mathrm{Mg}=12 ; \mathrm{Ca}=12+8(=20)$; $\mathrm{Sr}=20+24(=44) ; \mathrm{Ba}=44+24$

Por sua vez, no ano seguinte, J. B. Dumas (1800-1884) evidenciava a regularidade dos pesos atómicos dos elementos $\mathrm{N}=14 ; \mathrm{P}=14+17$; As $=14+17+44 ; \mathrm{Sb}=14+17+2 \times 44$; $\mathrm{Bi}=14+17+4 \times 44$, apresentando todos eles muitas propriedades semelhantes; e notou também a regularidade na diferença entre os pesos atómicos dos elementos $\mathrm{Cl}, \mathrm{P}, \mathrm{Br}$, As, l e Sb da mesma série: $\mathrm{Cl}-\mathrm{P}=\mathrm{Br}-\mathrm{As}$ $=\mathrm{I}-\mathrm{Sb}=5[15]$.

Regularidades semelhantes foram sendo apontadas, entre outros, por A. E. Béguyer Chancourtois (1820-1886), J.A.R. Newlands (1837-1898), W. Odling (1829-1921), S. Cannizzaro (1826-1910) e J. Lothar Meyer (1830-1895) até chegarmos a D. I. Mendeleev [16]. De um modo ou de outro, todos eles apontavam no sentido duma Lei Periódica que traduzia a variação dos pesos atómicos de uns elementos para outros. "As propriedades dos elementos dependem de um modo periódico dos seus pesos atómicos" foi a formulação simplificada que Mendeleev encontrou para essa Lei. Na comunicação científica que apresentou no Segundo Congresso dos Naturalistas Russos, realizado em Moscovo, em 1869, com a Tabela Periódica dos Elementos que construíra com base nessa mesma formulação, Mendeleev explicitou-a em oito princípios correspondentes a observações directas ou deduções nelas apoiadas, a saber [17]:

1. os elementos, quando dispostos segundo os seus pesos atómicos, mostram uma clara periodicidade de propriedades;

2. elementos com propriedades químicas semelhantes têm pesos atómicos muito próximos, iguais ou com um aumento regular;

3. o arranjo dos elementos, ou de grupos de elementos, na base dos seus pesos atómicos, corresponde às suas valências;

4. os elementos mais abundantes na natureza têm pesos atómicos muito baixos e propriedades muito bem definidas; são elementos típicos;

5. a magnitude do peso atómico determina o carácter de um elemento;

6. a ordenação dos elementos conhecidos segundo o seu peso atómico revela que há ainda muitos elementos não conhecidos cuja descoberta se espera;

7. em alguns casos, o peso atómico de um elemento poderá ser corrigido na base dos pesos atómicos de elementos que lhe são adjacentes na classificação periódica;

8. podem prever-se algumas características de alguns elementos com base na posição que ocupam na tabela periódica decorrente do seu peso atómico.

Guiado por estes princípios, Mendeleev construiu a sua Tabela Periódica dos elementos, uma tabela claramente dotada dum certo carácter profético, posto que grande parte das qualidades físicas e químicas dos elementos se podem deduzir do lugar que nela ocupam e vice-versa. Tanto assim que para que a regularidade se verificasse, Mendeleev admitiu que o peso atómico de alguns elementos então conhecidos estava mal determinado, devendo ser alterada a sua posição na Tabela; e admitiu também que haveria elementos ainda não descobertos que corresponderiam a determinadas posições da Tabela. Quanto a pesos atómicos mal determinados, vir-se-ia a concluir ser esse o caso de elementos como o ítrio, o índio, o disprósio, o cério, o érbio, o lantânio, o tório ou o urânio; e quanto a lugares vagos que viriam a ser ocupados por elementos posteriormente descobertos, podem referir-se os casos dos lugares que viriam a ser ocupados pelo alumínio e pelo silício que cederam o seu lugar ao gálio e ao germânio, descobertos mais tarde.

No subsequente desenvolvimento dos modelos atómicos formulados pela Mecânica Quântica da Física do século $\mathrm{XX}$, com os pesos atómicos a serem substituídos pelos números atómicos, as observações directas e 
as deduções nelas apoiadas que permitiram a Mendeleev a formulação dos princípios em que baseou a sua classificação periódica, encontraram o suporte matemático de que a ciência racional carece e denodadamente procura. Do ponto de vista da metodologia usada, o formalismo matemático avançado pela Mecânica Quântica explica satisfatoriamente a classificação periódica apresentada, num espantoso sucesso de racionalização, sem lhe retirar o seu carácter empírico. Porém, se olharmos para além da organização metodológica e nos fixarmos numa análise de cariz ontológico, as considerações filosóficas que a mesma suscita são muito menos apodícticas e a explicação muito mais complexa em que se confrontam e misturam a ordem aritmética e a ordem geométrica que encontramos no universo e trazem à colação a essência última do ser de um elemento.

\section{DA HÉliCE TELÚRICA DE Chancourtols À Dicotomia cósmica de Mendeleev}

Como dissemos já, antes de Mendeleev ter apresentado a sua classificação periódica dos elementos, em 1869, baseada nos pesos atómicos, já outros químicos haviam tentado fazê-lo. Mendeleev fez questão de se demarcar dessas tentativas, referindo concretamente que desconhecia por completo as tentativas que haviam feito Béguyer de Chancourtois, em 1862, na França, John Newlands, em 1865, na Inglaterra, e J. Lothar Meyer, em 1864, na Alemanha [18]. Não deixa de ser curiosa a sua referência explicita a estes três autores. E não podemos deixar passar despercebida a sua referência a Chancourtois, relacionando-a com a posição de excepção que defendeu para o elemento telúrio, na Tabela, relativamente ao iodo. Embora o peso atómico do telúrio fosse 128 e o do iodo 127 e não havendo nada que indicasse que estes pesos atómicos pudessem estar errados, Mendeleev defendeu que o telúrio deveria ocupar um lugar antes do iodo. $E$ assim procedeu na sua classificação, posteriormente confirmada pela classificação periódica baseada nos números atómicos. As razões para este seu procedimento não são totalmente claras, já por se não apoiarem numa possível determinação errada dos pesos atómicos relativos então conhecidos para qualquer dos dois elementos, já por incidirem numa diferença de apenas uma unidade, ao tempo em que ainda se não apagara por completo a ideia de Newton sobre as partículas corpusculares como partículas sujeitas a um certo desgaste [19], com um peso que não seria exactamente o mesmo para todos os corpúsculos de um mesmo elemento. Ainda em 1887, falando do peso atómico do cálcio, J.C. Marignac (1817-1894) dá-nos conta deste entendimento ao afirmar claramente que o peso atómico mais não é que o valor médio de pesos atómicos variáveis entre os quais os átomos dum mesmo elemento oscilam, num intervalo muito estreito, de tal modo que embora a maioria dos átomos de cálcio tenha um peso real de 40 , haverá alguns cujo peso poderá ser correctamente representado por 39 ou 41 e outros, embora em menor número, por 38 ou 42 [20].

Tomando para base de trabalho os pesos atómicos apresentados por S. Cannizzaro em 1858, Béguyer Chancourtois, em 1862, ordenou os elementos químicos então conhecidos dispondo-os pela ordem crescente do seu peso, numa disposição em espiral, baseada no peso atómico do oxigénio, já estabelecido na época como 16. Para tanto, tomou um cilindro, dividindo a sua base em 16 segmentos iguais. Traçou uma hélice na superfície do cilindro, de modo que formasse um ângulo de $45^{\circ} \mathrm{com}$ o seu eixo. Sobre ela dispôs os elementos em ordem crescente de pesos atómicos, que foram tomados como ordenadas sobre várias geratrizes. A hélice atravessava as geratrizes a distâncias cujos valores eram múltiplos de 16 . Verificou que os elementos com pesos atómicos diferindo em 16 unidades, se encontravam sobre uma mesma geratriz e correspondiam a elementos com propriedades químicas semeIhantes. Assim acontecia, por exemplo, com o lítio, o sódio e o potássio, com pesos 7,23 e 39, respectivamente, todos eles ocupando lugares sobre uma mesma vertical; como acontecia com o oxigénio, o telúrio e o selénio, numa noutra linha. No centro do enrolamento estava o telúrio. Daí o nome de "Hélice Telúrica" com que Chancourtois designou esta sua disposição classificativa dos elementos. Admirador profundo da teoria dos números de Pitágoras, Chancourtois interpretou a grande semelhança entre os elementos distribuídos sobre uma mesma geratriz da sua hélice telúrica como prova de que a repetição periódica das propriedades dos elementos químicos se devia ao facto de as propriedades dos corpos serem as propriedades dos números. A posição central do telúrio na geratriz da distribuição helicoidal dos elementos mais não seria que a manifestação natural do carácter de regenerador da vida de que este elemento seria dotado1. Deste modo, para além de realçar o fundamento numérico das propriedades elementares, a distribuição helicoidal dos elementos evidenciaria o escalonamento hierárquico dos mesmos no processo da sua origem e formação, associado ao carácter simbólico e mítico da unidade de todas as coisas, na sua relação com o devir cósmico [21].

Sem conhecimento da classificação periódica dos elementos apresentada por Chancourtois, na sua arrumação dos elementos químicos pela ordem crescente dos respectivos pesos atómicos, Mendeleev chegou a uma Tabela com os elementos distribuídos por oito colunas verticais (os Grupos ou Famílias) e doze linhas horizontais (os Períodos ou Séries). De fora ficaram todas as considerações com laivos das razões míticas e simbólicas de Chancourtois. Todavia, ao tentar fundamentar a ordem conseguida $e$ ao interrogar-se sobre a essência última dos elementos como tais, não conseguiu ficar-se por meros critérios físicos e químicos e com naturalidade extravasou os limites do estrito experimentalismo e dedutivismo da Física e da Química. Nem os caracteres químicos, nem os caracteres físicos dos diferentes elementos seriam só por si suficientes para diferenciar totalmente os corpos químicos. Os caracteres da harmonia simples da distribuição na vertical e na horizontal, em separado, não são totalmente independentes da sua distribuição na diagonal. Mendeleev é bem explícito a este propósito: 
"assim, por exemplo, o lítio, em muitos aspectos, parece-se com o potássio, mas, em muitos outros, parece-se com o magnésio; de modo semelhante, o glucínio apresenta grandes semelhanças com o alumínio e com o magnésio; o tálio parece-se com o chumbo e com o mercúrio, apresentando também várias propriedades comuns ao lítio e ao potássio" [22].

A regularidade periódica dos elementos na vertical e na horizontal da Tabela Periódica de Mendeleev está profundamente interligada com a sua distribuição na diagonal, num emaranhado complexo em que ressai uma profunda dicotomia cósmica. O mundo dos elementos químicos não escapa a uma cisão dicotómica que nos transporta à dicotomia cósmica de todo o universo: o céu e a terra, o macrocosmos e o microcosmos, o masculino e o feminino; essa dicotomia a que a Tábua de Esmeralda se refere quando diz que "o que está em baixo é como o que está em cima e o que está em cima é como o que está em baixo para que se cumpra o milagre da unidade".

De facto, nela encontramos duas regiões ou pólos separados por uma região de intermediários formada por uma espécie de híbridos: os elementos alcalinos e alcalino-terrosos à esquerda; os halogéneos e calcogéneos à direita. De um lado os electronegativos, ávidos de electrões; do outro, os electropositivos. À direita, os não-metais que formam facilmente óxidos ácidos e não possuem nem dureza, nem brilho, nem capacidade de condução calorífica ou eléctrica significativas; à esquerda, os metais, duros, brilhantes e com notável poder de condução, com seu carácter básico. A separá-los, os metalóides, híbridos em que se misturam os caracteres dicotómicos dos metais e não-metais. De um lado, o solo; do outro o aéreo. A oposição dicotómica entre os elementos localizados na parte esquerda da Tabela e os localizados na parte direita, ao longo das diferentes Séries ou Períodos para os diferentes Grupos ou Famílias, acentua-se quando analisada em sentido diagonal. Não é por acaso que o cume da dicotomia se verifica entre os elementos na parte esquerda inferior da Tabela e a parte direita superior, as extremidades da diagonal do arranjo geométrico que constitui a Tabela, onde se localizam, respectivamente, os mais alcalinos dos alcalinos, o césio e o frâncio, e os mais "halogéneos" dos halogéneos, o flúor e o cloro [23].

Esta dicotomia cósmica patente na Tabela Periódica de Mendeleev leva-nos a considerações de ordem ontológica que ultrapassam a própria metodologia subjacente à mera ordenação dos elementos pela ordem crescente dos seus pesos atómicos. Nela poderemos encontrar possíveis razões para alguns dos procedimentos que marcam a sua história. Porque não hesitou Mendeleev em colocar o telúrio (peso atómico 127,61), antes do iodo (peso atómico 126,92) ou o cobalto (peso atómico 58,93 ) antes do níquel (peso atómico 58,70), invertendo a ordem natural dos respectivos pesos atómicos? E como the foi possível postular a existência de elementos ainda não conhecidos que deveriam ocupar alguns lugares que ousou deixar em aberto na tabela que construiu? Porque, conformando-se com o que se passa no universo, nomeadamente a conjugação dos opostos, se impunha que na classificação dos elementos que o compõem, a identidade estrutural, factor de continuidade, se conjugue com toda uma multiplicidade de figuras e formas que estão na origem da descontinuidade e da variedade das coisas existentes. Mendeleev foi capaz de o fazer, manipulando os números e sobrepondo-se à "realidade" que o experimentalismo científico the oferecia. Ao contrário do que defendera Chancourtois, Mendeleev não aceitava que as propriedades dos corpos fossem meramente as propriedades dos números.

\section{Conclusão}

O futuro viria em apoio do procedimento geral de Mendeleev. Mas, Curiosamente, viria centrar a questão, uma vez mais, no número. Não o número que traduz o peso atómico, mas o número que exprime a quantidade electrónica de cada elemento. Mais que associada ao peso atómico de cada elemento, a sua dualidade cósmica decorre, ontologicamente, da quantidade de electrões que possui, contrabalançada, no estado natural dos corpos, pela quantidade de protões, a dicotomia do negativo/positivo. O peso atómico de cada elemento depende do número de protões, neutrões e electrões que possui; dos diferentes pesos de cada uma destas partículas decorre que a ordem crescente do peso relativo de dois elementos não coincida necessariamente com a ordem crescente do número das suas partículas de cargas opostas que os compõem, os protões e os electrões, a verdadeira causa da dicotomia cósmica do mundo que formam. Em particular, as propriedades químicas dependem fundamentalmente do número das partículas com carga negativa, os electrões, a grande base das interacções moleculares que as ditam, mas sem ignorar nunca a carga positiva com que se dá a interacção. Claramente, é a dicotomia cósmica dos elementos que determina a sua mais correcta classificação periódica. Só a relação de proximidade entre os pesos atómicos dos elementos e o conjunto de cargas opostas que neles existem, justifica a validade da classificação periódica apresentada por Mendeleev, num quadro do carácter aproximativo que dá forma a qualquer sistema de explicação química.

Neste quadro, cem anos depois da morte de Mendeleev, a metafísica da Química continua a discutir o carácter dual do conceito de elemento químico [24].

Nota

${ }^{1} \mathrm{Na}$ actual Tabela Periódica dos elementos o telúrio, com o número atómico 52 , continua a ocupar um lugar verdadeiramente central no conjunto dos cento e pouco elementos químicos que a compõem.

\section{REFERÊNCIAS}

[1] D.Q. Posin, Mendeleev, The Story of a Great Chemist, Whittlesey House, New York, 1948

[2] Ver, por exemplo, V.A.Kostikov, "The Mendeleev Archives and Museum of Leningrad University", J. Chem. Educ. 
37 (1960) 625-628, Fig. 2 e Fig.3

[3] J.R.Partington, A History of Chemistry, vol.IV, The MacMillan Press Ltd, London, 1972, 894-899.

[4] Eric R. Scerri, The Periodic Table: Its Story and Its Significance, Oxford University Press, London, 2007.

[5] Seymour Mauskopf, "Elemental Deductions”, American Scientist 95 (2007) 456-457.

[6] John Dalton, A New System of Chemical Philosophy. 3 vols., Manchester, 1808, 1810, 1827.

[7] H. Davy, "Bakerian lecture", Phil. Trans. 101 (1811) 1-35.

[8] J.R.Partington, o.cit.,142-177.

[9] Idem, 76-90.

[10] Idem,199-202.
[11] Idem, 205-213.

[12] Ann. Phil. 6 (1815) 321-330.

[13] J. W. Döbereiner, Ann. Phys. 56 (1817) 331.

[14] M. Pettenkoffer, Gelehrten Anzeiger 30 (1850) 261-272.

[15] J. B. Dumas, The Athenaeum. Journal of Literature,Science and Fine Arts (1851) 750; L'Institut 19 (1851) 302.

[16] J.R. Partington, o.cit., 883-889.

[17] D.I. Mendeleev, J.Prakt. Chem. 106 (1869) 251 citado in J.R. Partington, o.cit., 894-895

[18] D.I. Mendeleev, Principles of Chemistry, Tom.II, London, 1905, 489.

[19] I. Newton, Optics, or, a Treatise of the Reflections, Refractions, and Colours of
Light, London, 1704. Optics, Quest. 31

[20] J.C. Marignac, Arch. Sci. Phys. Nat. 17 (1887) 373-389 citado in J. R. Partington, o.cit. p.882.

[21] B.Chancourtois, Comptes Rendus hebdomadaires dês Séances de l'Académie dês Sciences, Paris, 1863.

[22] D.I Mendeleev, Principles of Chemistry, Tom.II, London, 1905, 460.

[23] François Dagognet, Tableaux et Langages de la Chimie, Ed. du Seuil, Paris, 1969,153ss.

[24] Eric R.Scerri, "Some Aspects of Metaphysics of Chemistry and the Nature of the Elements", Hyle 11 (2005)127-145 e toda a vasta bibliografia básica aí referida.

\section{Actualidades Científicas}

\section{A estufa de Vénus}

O conhecido efeito de estufa intenso verificado na atmosfera do planeta Vénus pode ser provocado pela existência nesta de uma forma rara de dióxido de carbono, em que um dos átomos de oxigénio contém dez neutrões, em vez dos habituais oito, característicos do isótopo de oxigénio mais comum.

O enigma começou com a chegada da Venus Express da Agência Espacial Europeia (ESA) a Vénus, em Abril de 2006. Uma equipa europeia chefiada por Jean-Loup Bertaux, do CNRS, França, e Ann-Carine Vandaele, do Institut d'Aeronomie Spatiale da Bélgica, usou o espectrómetro atmosférico de infra-vermelho da sonda (SOIR) para medir ocultações solares, ou seja, espectros da luz que atravessa a atmosfera de Vénus, durante o período do pôr do sol. Desta forma, os cientistas poderiam detectar e estudar a forma como comprimentos de onda específicos são absorvidos pela atmosfera de Vénus. Estes comprimentos de onda e a extensão da absorção permitem identificar os gases presentes na atmosfera, assim como a sua quantidade relativa.

Através desta técnica, a equipa de investigadores detectou a assinatura química do chamado isotopólogo de dióxido de carbono, que constitui $1 \%$ do dióxido de carbono presente na Terra. De facto, nas observações efectuadas surgia uma misteriosa linha espectral nos 3.3 micra, na região do infravermelho médio, que estranhamente aumentava à medida que se entrava mais profundamente na atmosfera do planeta. Inicialmente, a equipa não divulgou estes resultados, já que suspeitava que se podia dever à presença de uma molécula orgânica. No entanto, nenhuma molécula orgânica conhecida se ajustava satisfatoriamente à assinatura química observada.

Posteriormente, em Dezembro de 2006, Mike Mumma do NASA's Goddard Space Flight Center em Maryland, EUA, contactou a equipa SOIR na perspectiva de saber se esta teria observado algo na região de $3.3 \mathrm{mi}$ cra, já que tinha verificado uma assinatura não identificada precisamente a esse comprimento de onda, usando telescópios apontados a Marte. As duas equipas compararam os resultados e verificaram que eram idênticos.

Como as atmosferas de Marte e de Vénus são compostas por $95 \%$ de dióxido de carbono (apesar da atmosfera venusiana ser muito mais densa), a equipa americana sugeriu que a assinatura se poderia dever à presença de um isotopólogo de dióxido de carbono. No entanto, não se tinha observado anteriormente qualquer linha espectral a 3.3 micra para essa molécula.

Assim, uma investigação levada a cabo por três grupos independentes, um liderado por Mumma nos EUA, Sergei Tashkun e Valery Perevalov da Tomsk State University da Russia e Richard Dahoo do Service d'Aeronomie du $C N R S$, França, levou à conclusão que a assinatura podia ser causada por uma transição de energia rara, só possível num isótopo.

Esta transição permite ao isotopólogo de dióxido de carbono absorver mais energia e assim contribuir ainda mais para o efeito de estufa em Vénus. Felizmente, existe 250000 vezes menos dióxido de carbono na atmosfera da Terra do que na de Vénus, e assim, a presença de apenas $1 \%$ de isotopólogo não contribui significativamente para acentuar o efeito de estufa na Terra. (adaptado de webzine Reactive Reports 69, 2007 e do Press Release de 10 de Outubro de 2007 da ESA: http://www.spaceref.com/news/ viewpr.rss.html?pid=23769).

Paulo Brito 


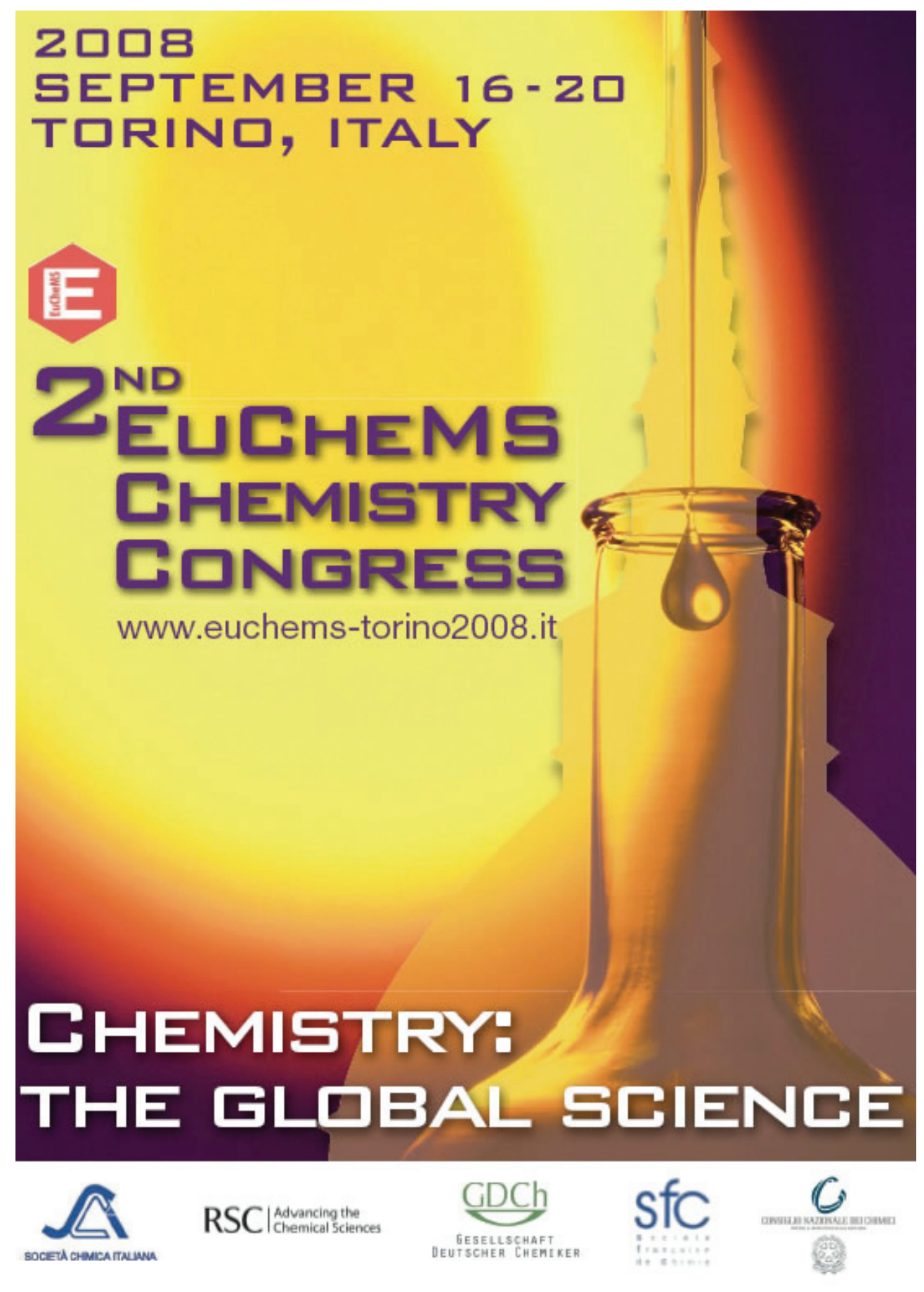

O 2ํㅡㄹ Congresso Europeu de Química será co-organizado pela EuCheMS (Associação Europeia para as Ciências Química e Moleculares, da qual a SPQ é sócia fundadora) e pela Sociedade Italiana de Química. É um evento muito importante para todas as Sociedades de Química Europeias, sendo esperada uma grande participação dos seus membros, oriundos de Universidades, Indústria e de Instituições Públicas e Privadas de Investigação e Análise.

Como determinado pela EuCheMS, os principais objectivos destes congressos, que reúnem todos os ramos das ciências química e molecular, são a promoção da química e da ciência química e molecular na fronteira do conhecimento, a dinamização da colaboração entre cientistas a trabalhar em investigação, na indústria e na educação, para desenvolver a química Europeia e a melhoria da imagem da química na sociedade.

O Congresso será organizado em sessões comuns, através de lições plenárias proferidas por cientistas de renome, e em sessões paralelas, focando áreas importantes da química. O programa destas sessões paralelas incluirá lições temáticas e lições convidadas, assim como comunicações orais e em poster, seleccionadas dos resumos submetidos. 